\title{
Violations of medical confidentiality: opinions of primary care physicians
}

Bernice S Elger

\begin{abstract}
Background

Physicians should be able to distinguish situations where they need to protect confidentiality from those where they could be obligated to reveal information. Data are scarce concerning physician's attitudes in daily situations where violations of confidentiality are avoidable. Physicians should be aware of situations where patients are identifiable.
\end{abstract}

Aim

To solicit participation of primary care physicians in a teaching intervention and to explore participants' opinions on violations of confidentiality.

Design of study

A questionnaire presented seven vignettes describing avoidable violations of confidentiality (for example, without patient consent a physician mentions a politician's illness their spouse). Participants answered on a scale of $0-3(0=$ no violation and $3=$ serious violation). All contacted physicians were invited to a teaching session during which the study results were discussed.

Method

Three-hundred and seventy-eight members of the Association of Physicians in Geneva (community physicians) working in primary care medicine, and 130 GPs and internists working at the University Hospital of Geneva (hospital physicians) took part. Physicians' answers were compared to responses from Swiss, UK, and other European law professors, and from 311 medical and law students in Geneva.

\section{Results}

Between 4\% (case 6) and 57\% (case 2), of physicians thought that no violation occurred. Law professors attributed the scores to each case as 3, 3, 2, 3, 2, 3, 3; the means of physicians were: $1.9,1.4,0.7,1.4$ (hospital physicians)/ 1.9 (community physicians), 0.4 , 1.6, 2.6. In most cases, physicians' and students' answers were similar. A significantly higher percentage of community physicians than hospital physicians and students thought that a physician violates confidentiality if they provide the list of their patients to the police for the investigation of the theft of a purse in the waiting room.

\section{Conclusion}

Physicians need to be fully aware of their obligations towards patient confidentiality. Avoidable breaches of confidentiality occur when colleagues and authorities (such as police and those in a judicial context) ask for information.

Keywords

attitudes of health personnel; confidentiality; ethics; legal; primary care; questionnaire.

\section{INTRODUCTION}

Confidentiality is a central aspect of the physician-patient relationship. ${ }^{1}$ Codes of professional ethics and the laws of most countries affirm its

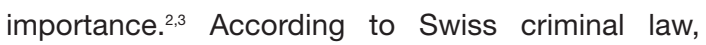
violations of medical confidentiality are punished by a fine or a prison sentence.

Nevertheless, the law authorises some breaches of confidentiality, which most commentators would find ethically justified. In the US and Australia, reporting of suspected child abuse is mandatory. ${ }^{4-6}$ In Switzerland, similar to the UK and many other countries, ${ }^{7}$ the physician is allowed - but not obliged - to breach confidentiality in the case of child abuse.

In most countries, a breach of confidentiality is permitted to warn third parties against the wish of the patient if: reasonable efforts to elicit voluntary consent to disclosure have failed; harm is imminent; the harm that identifiable individuals would suffer is serious; there is a high probability both that harm will occur if the information is withheld and that the disclosed information will efficiently avert harm; and if appropriate precautions are taken to ensure that only the information needed to prevent the harm in question is disclosed. ${ }^{8,9}$

Several studies have shown that physicians disagree whether and when breaches are justified when presented with potentially socially threatening behaviour by their patients. ${ }^{10-13}$ Physicians have conflicting opinions concerning the reporting of competent victims of violence who oppose the disclosure, ${ }^{14-16}$ concerning giving information to sexual partners of an HIV-positive test against the will of the

BS Elger, MD, PhD, MA(theology), associate professor, Center for Legal Medicine, University of Geneva, Switzerland.

Address for correspondence

Professor Bernice Elger, Centre Médical Universitaire, 1, rue Michel Servet, 1211 Geneva 4, Switzerland.

E-mail : Bernice.Elger@unige.ch

Submitted: 20 February 2009; Editor's response: 16 April 2009; final acceptance: 14 July 2009.

(C)British Journal of General Practice

This is the full-length article of an abridged version published in print. Cite this article as: Br J Gen Pract 2009; DOI: 10.3399/bjgp09X472647. 
patient, ${ }^{17-20}$ and when confidentiality conflicts with the patient's own good.21-23 Some physicians consider confidentiality as an absolute rule, whereas many try to balance confidentiality and the prevention of harm. ${ }^{21,24}$

Empirical evidence indicates that erosion of confidentiality has negative consequences for society, because many victims of violence and sick patients would, fearing disclosure, abstain from seeking medical care. .116,25 $^{1,16}$

Apart from these ethically difficult issues, clearly unjustified breaches of confidentiality also occur. ${ }^{26-33}$ Examples are exchanges of confidential information in cafeterias, elevators, waiting rooms, ${ }^{34}$ with physician's spouses, or at social occasions. Some of these breaches might occur accidentally because physicians do underestimate the seriousness of the breach, ${ }^{35}$ or the risk that in spite of not naming the patient, he or she might be identifiable because of some details mentioned. Most of these breaches are avoidable. Some hospitals place signs in public areas to remind physicians of the risk of overheard conversations..$^{27,36}$ Empirical studies show that many patients value confidentiality highly, ${ }^{11,25,26,28,32,37}$ and that they are not aware of how often physicians disclose confidential information without any justification. ${ }^{26}$

A third category of breaches occurs because of ignorance of the legal obligations..$^{38-42}$

Few studies have examined avoidable breaches of confidentiality due to non-necessary, negligent, or precipitated disclosure of private information to authorities. The present study tried to fill this gap and had four aims. The first was to solicit interest of physicians in a teaching intervention about confidentiality at the university hospital. The second was to investigate how participants evaluated the seriousness of different confidentiality violations; it was expected that motivation to avoid breaches of confidentiality that are judged to be of minor importance would be lower than the motivation to avoid serious violations. Many of the hospital physicians later become community physicians. The third aim was therefore to investigate whether the two groups have different attitudes, in order to better define the needs for teaching during the hospital training. The final aim was to investigate whether respect for confidentiality is a general trait: this would mean that some physicians consider breaches of confidentiality in general less serious than others; it could also mean that some physicians have a different interpretation of the need for confidentiality or have incomplete knowledge concerning legal and ethical requirements.

\section{METHOD}

In January 2004, standardised questionnaires were sent to all 616 members of the Association of Physicians in Geneva (AMG, abbreviated from now on

\section{How this fits in}

In contemporary healthcare systems and daily life, physicians encounter many situations at risk for violations of confidentiality. Considerable attention has been paid to cases where physicians could be under an obligation to violate confidentiality in order to prevent harm to a third party. Data are scarce concerning physicians' attitudes in daily situations where violations of confidentiality are avoidable. Physicians regularly receive requests from colleagues or authorities (such as police, coroners, or forensic experts), to transmit patient information. They need to be able to distinguish situations where they are required to protect confidentiality from those where they could be obliged to reveal information. The present study explores physicians' opinions in seven practical, everyday situations and identifies cases where the need to grant confidentiality and the seriousness of violations are

underestimated. Physicians should be aware of situations where patients are identifiable. Routine scrutiny helps to reduce avoidable violations.

as 'community physicians') who were registered as physicians practising in private practice in primary care, either internal or general medicine, and to all 250 physicians working in the department of general internal medicine or primary care outpatient clinic of the University Hospital of Geneva (hospital physicians). The hospital physicians were mostly future primary care physicians pursuing specialty training as a GP or general internist. One questionnaire reminder was sent 2 months later. The cases are summarised in Box 1.

Participants were asked to indicate, on a scale of 0-3 for each case, whether confidentiality had been violated and, if yes, how serious they considered the violation. After each case, physicians and law professors were given the opportunity to write comments. Responses were scored from 0 (no violation of confidentiality), 1 (violation without importance), 2 (violation for which the physician should receive a warning), to 3 (serious violation).

The researchers informed physicians that the aim of the study was to solicit physicians' participation in a teaching programme on ethical and legal issues related to confidentiality and privacy rights. The letter to the physicians announced that the seven cases presented in the questionnaire, as well as the results of physicians' answers, were being discussed as part of a teaching module on confidentiality during a cycle of courses. These courses were organised weekly at the university hospital for the sample that was contacted (internists and GPs in private practice as well as in the hospital). All contacted physicians were invited to the teaching session.

In order to establish a local and European 'gold standard' about the seriousness of the violations from a legal viewpoint, the questionnaire was also sent to three professors of criminal law teaching at the University of Geneva as well as to a sample of 10 European law professors specialising in health law and 


\section{Box 1. The seven hypothetical cases presented in the} questionnaire.

\section{Case 1a}

An internist treats in their private office one of the five male politicians from the cantonal government for a cardiac arrhythmia. The physician mentions this fact to their (the physician's) spouse, who is also a physician, indicating the politician's name.

Case $1 b$

Same as case 1a, but the physician mentions the patient's diagnosis to their (the physician's) spouse and the political function (member of the cantonal government), but not the patient's name.

Case 2

A patient informs her gynaecologist that she is not satisfied with their treatment and tells them the name of the gynaecologist she is going to see for consultation from now on. The first gynaecologist phones their colleague to inform them that the patient suffers from active hepatitis $\mathrm{C}$.

Case 3

A patient's purse has been stolen from their coat, which they had left in the waiting room of their GP. At the request of the police the GP provides the list of all patients they have seen on the day of the theft.

Case 4

At the request of a forensic pathologist, a surgeon informs them about the medical record of a person who disappeared, in order to compare it with the autopsy record of a cadaver that has been found in the nearby river.

Case 5

A young woman consults a local accident and emergency service with several broken teeth and other facial injuries of traumatic origin. She says she has been beaten by the police during the evacuation of a squat. During a dinner party with friends, the physician who has seen the woman in the emergency department mentions these facts without providing the name of the patient, but indicating the address of the evacuated squat. Among their friends is a lawyer who is member of the cantonal parliament.

Case 6

A computer specialist who is repairing the computer of a dermatologist prints out a list with the names of all persons who have been seen on consultation during the past year with indication of the type of treatment received and the paid and unpaid bills. considered significant if $P$-values were $\leq 0.05$. ANCOVA and linear regression were used for multivariate analysis to establish the variance of responses explained by the type of participant (physician or medical/law student).

\section{RESULTS}

Responses were received from one law professor respectively from Italy, Denmark, Germany, and from two law professors from the UK. The responses of European law professors did not differ significantly from those of their Swiss colleagues, except for case 4 (Appendix 1).

A total of 508 physicians sent in completed questionnaires. The participation rate was $56 \%$ for community physicians $(n=378)$ and $52 \%$ for hospital physicians $(n=130)$. The mean age of community physicians was $51 \pm 8.4$ years, compared to $36 \pm$ 6.7 years for hospital physicians $(P<0.01)$. The mean total years of practice as a physician was $24 \pm 8.7$ for community physicians and $9 \pm 6.3$ for hospital physicians. Community physicians had been working in private practice for $14 \pm 8.8$ years, whereas only a minority of hospital physicians were working in private practice (mean $0.4 \pm 1.9$ years, $P<0.01$ ). Community physicians had practised for a considerable number of years in the hospital before starting a private practice (11 \pm 6.0 years) a mean of 2 years more than physicians working in the university hospital: $9 \pm$ 5.8 years, $P<0.01$. The majority of participants were internists: $86 \%$ of hospital physicians and $68 \%$ of community physicians $(P<0.01)$.

Among both groups of physicians, the same percentage of participants $(40 \%, P=0.97)$ had a subspecialty (such as, oncology, infectious diseases, or other) in addition to the specialty exam in internal or general medicine (in Switzerland, general medicine is considered a specialty requiring 5 years of training and a board certification).

Participants' responses were analysed with respect to two questions: did participants recognise that a breach of confidentiality took place; and did participants attribute scores that were similar to the gold standard?

The percentage of physicians who thought that no violation occurred varied in an important way according to the type of case; for example $4 \%$ in case 6 , compared to $57 \%$ in case 2 . Community physicians' attitudes did not differ significantly from the attitudes of hospital physicians except for case 3: $14 \%$ (community physicians) versus $32 \%$ (hospital physicians, $P<0.01)$ were convinced that no violation took place.

The means scores of law professors, physicians, and law and medical students who answered the same questionnaire in a previous study are compared in 
Table 1 and Table $2 .{ }^{43}$ In case 2, physicians identified the violation of confidentiality and their severity more correctly than young law students in Geneva did. In case 3, hospital physicians did not differ from students, but physicians in private practice identified the violation more often than hospital physicians and medical and law students. For the comparison of the results in case 1 it should be noted that physicians had two versions of the case, whereas students only had one that was similar but not identical to case $1 b$ : in the student's version, it was assumed, but not explicitly stated, that the physician does not mention the patient's name, but only refers to him as one of the five state councillors.

A total of $11 \%$ of physicians, $9 \%$ of medical students, and $7 \%$ of law students thought that a violation of confidentiality had taken place in all cases, in line with the gold standard (Table 1). In only two cases was the proportion of physicians who mistakenly believed that no violation occurred below $10 \%$ : in case 1a (politician's name is mentioned) and case 6 (computer specialist).

A total of $83 \%$ of physicians identified the violation of confidentiality in case 5 (squat). A similar percentage (74\% versus $80 \%, P=0.200$ ) of hospital and community physicians thought that the patient is identifiable. Those who thought that the patient is identifiable expressed significantly different opinions about the case (they judged that an important violation occurred: score $1.9 \pm 0.8$ ) than those who thought that the patient is not identifiable (score $0.6 \pm 0.6, P<0.001$ ).

In two cases, the majority of physicians $(76 \%$ in case 4 and $57 \%$ in case 2) considered that no violation had taken place. In most cases, mean scores were 1 to 2 points lower than the gold standard. Only in case 6 was the mean score of physicians very close to the gold standard (2.7 compared to 3).

Responses were influenced significantly by the type of case. The study analyses did not show a trait towards more or less respect of confidentiality; that is, the hypothesis that some physicians respect confidentiality in general less than others, due to education, ethical choices, or other factors, was not confirmed. Reliability analysis showed a Cronbach's $\alpha$ of 0.34 for students and physicians for all six cases (using only variant $b$ for case 1 ). It was highest among community physicians ( $\alpha=0.57$ for seven cases including case $1 \mathrm{a}$, and 0.48 without case $1 \mathrm{a}$ ), followed by hospital physicians ( $\alpha=0.48$ for seven cases and 0.34 without case 1a) and medical students $(\alpha=0.13$ for six cases). Reliability was lowest for law students ( $\alpha$ $=0.06$ for six cases).

Factor analysis revealed one factor explaining $34 \%$ of the variance of responses to questions $2,3,4$, and 5 , and one factor explaining $51 \%$ of the variance of the responses to questions $1 \mathrm{~b}$ and 6 . One factor explained

\section{Table 1. How many times the score 0 (no violation of confidentiality) has been attributed among physicians, medical, ${ }^{43}$ and law students. ${ }^{43}$}

\begin{tabular}{|c|c|c|c|c|}
\hline $\begin{array}{l}\text { Score } 0 \text { attributed } \\
\text { per } 6 \text { cases } \\
\left(\text { without case } 1 a^{a} \text { ) }\right.\end{array}$ & $\begin{array}{l}\text { Physicians } \\
(n=508), \\
n(\%)\end{array}$ & $\begin{array}{c}\text { Medical and } \\
\text { dental students } \\
(n=79), n(\%)\end{array}$ & $\begin{array}{l}\text { Law students } \\
\qquad \begin{array}{c}n=232) \\
n(\%)\end{array}\end{array}$ & $\begin{array}{c}\text { Total } \\
(n=819), \\
n(\%)\end{array}$ \\
\hline Never & $58(11.4)$ & $7(8.9)$ & $15(6.5)$ & $80(9.8)$ \\
\hline Once & $153(30.1)$ & $20(25.3)$ & $42(18.1)$ & 215 (26.3) \\
\hline Twice & $162(31.9)$ & 35 (44.3) & $90(38.8)$ & $287(35.0)$ \\
\hline Three times & $96(18.9)$ & $16(20.3)$ & $71(30.6)$ & $183(22.3)$ \\
\hline Four times & $35(6.9)$ & $1(1.3)$ & $13(5.6)$ & $49(6.0)$ \\
\hline Five times or more & $4(0.8)$ & $0(0)$ & $1(0.4)$ & $5(0.6)$ \\
\hline Total & $508(100)$ & 79 (100) & $232(100)$ & 819 (100) \\
\hline Mean $^{b}$ & $1.8 \pm 1.1$ & $1.8 \pm 0.9$ & $2.1 \pm 1.0$ & $2.0 \pm 1.1$ \\
\hline
\end{tabular}

${ }^{a}$ Case 1a was excluded in this comparison because it was not included in the questionnaire filled out by students. ${ }^{\mathrm{t}} \mathrm{t}$-tests: significant differences exist between law and medical students ( 2.1 versus $1.8, \mathrm{P}=0.01$ according to the test), as well as between physicians and law students (1.8 versus $2.1, \mathrm{P}<0.001)$, but not between physicians and medical students; Kruskal-Wallis for the three groups: $\mathrm{P}<0.001$.

$59 \%$ of the variance of the responses to question 2 and 4. The results of the factor analyses were similar in the subgroups of physicians and students.

Multivariate analysis entering all subgroups as dependent variables showed that the group variable that best explained the variances of the dependent variable 'non-identified violations among 6 cases' (Table 1) was the binary variable 'all physicians and medical students' versus 'law students'. However, this variable explained only $1.5 \%$ (adjusted R2) of the variance of the number of non-identified violations. More detailed results concerning the influence of demographic and other variables on the responses to the cases are reported elsewhere. ${ }^{44}$

\section{DISCUSSION}

\section{Summary of main findings and comparison with existing literature}

The legal requirement of confidentiality applies to all knowledge that a physician gains during their medical practice. The present study shows that only $11 \%$ of physicians recognised that in all six cases (without case 1a) a violation of confidentiality took place. Neither studying nor practising medicine seems to increase the ability to identify confidentiality violations, because physicians were similar to medical (and law) students among whom $9 \%(7 \%)$ identified all violations.

In two cases, case 1a and case 6 , the overwhelming majority of physicians recognised the breach of confidentiality. The authors' previous study showed that similar results were found among different samples of medical and law students. ${ }^{43}$ Most doctors from the present study agree that the physician violates confidentiality when they talk to their family about the disease of a politician and mentions the name of the 
Table 2. Participants who thought that no violation (0), a non-important violation (1), a violation for which the physician should receive a blame (2), or a serious violation (3) had taken place in the case scenarios 1-6.

\begin{tabular}{|c|c|c|c|c|c|c|c|c|}
\hline & $\begin{array}{l}\text { Hospital } \\
\text { physicians } \\
(n=130)\end{array}$ & $\begin{array}{l}\text { Community } \\
\text { physicians } \\
(n=378)\end{array}$ & $P$-value ${ }^{\mathrm{b}}$ & $\begin{array}{c}\text { Medical } \\
\text { students }^{\mathrm{a}} \\
(n=79)\end{array}$ & $\begin{array}{c}\text { Law } \\
\text { students } \\
(n=232)\end{array}$ & $P$-value & $P$-value ${ }^{d}$ & $\begin{array}{c}\text { Gold } \\
\text { standard }\end{array}$ \\
\hline \multicolumn{9}{|l|}{ Case $1 \mathrm{a} / \mathrm{b}$ (politician), $n(\%)$} \\
\hline 0 (no violation) & $8(6.2) / 23(18.4)$ & $25(6.8) / 69(18.9)$ & & 1b: 1 (1.3) & $1 \mathrm{~b}: 9$ (3.9) & & & \\
\hline 1 (not important violation) & $33(25.8) / 57(45.6)$ & $107(29.1) / 133(36.4)$ & & $20(25.3)$ & $90(39.0)$ & & & \\
\hline 2 (important violation) & $41(32.0) / 33(26.4)$ & $104(28.3) / 99(27.1)$ & & $46(58.2)$ & $94(40.7)$ & & & \\
\hline 3 (serious violation) & $46(35.9) / 12(9.6)$ & $132(35.9) / 64(17.5)$ & & $12(15.1)$ & $38(16.5)$ & & & \\
\hline Mean (SD) & $2.0(0.9) / 1.3(0.9)$ & $1.9(1.0) / 1.4(1.0)$ & $0.700 / 0.100$ & $1.9(0.7)$ & $1.7(0.8)$ & $<0.010$ & $<0.010$ & 3 \\
\hline \multicolumn{9}{|l|}{ Case 2 (hepatitis), $n$ (\%) } \\
\hline 0 (no violation) & $74(58.7)$ & $202(56.1)$ & & $36(45.6)$ & $156(67.5)$ & & & \\
\hline 1 (not important violation) & $29(23.0)$ & 77 (21.4) & & $23(29.1)$ & $38(16.5)$ & & & \\
\hline 2 (important violation) & $14(11.1)$ & $58(16.1)$ & & $16(20.3)$ & 26 (11.3) & & & \\
\hline 3 (serious violation) & $9(7.1)$ & $23(6.4)$ & & $4(5.1)$ & $11(4.8)$ & & & \\
\hline Mean (SD) & $0.7(0.9)$ & $0.7(1.0)$ & 0.500 & $0.8(0.9)$ & $0.5(0.9)$ & 0.100 & $<0.010$ & 2 \\
\hline \multicolumn{9}{|l|}{ Case 3 (theft), $n$ (\%) } \\
\hline 0 (no violation) & $41(32.3)$ & $50(13.8)$ & & $24(30.4)$ & $112(48.5)$ & & & \\
\hline 1 (not important violation) & $22(17.3)$ & $62(17.19$ & & $18(22.8)$ & $67(29.0)$ & & & \\
\hline 2 (important violation) & $37(29.1)$ & $140(38.7)$ & & $21(26.6)$ & $36(15.6)$ & & & \\
\hline 3 (serious violation) & $27(21.3)$ & $110(30.4)$ & & $16(20.3)$ & $16(6.9)$ & & & \\
\hline Mean (SD) & $1.4(1.1)$ & $1.9(1.0)$ & $<0.001$ & $1.4(1.1)$ & $0.8(0.9)$ & $<0.010$ & $<0.001$ & 3 \\
\hline \multicolumn{9}{|l|}{ Case 4 (cadaver), $n$ (\%) } \\
\hline 0 (no violation) & $100(79.4)$ & $265(74.9)$ & & $59(74.7)$ & $162(69.8)$ & & & \\
\hline 1 (not important violation) & $11(8.7)$ & $39(11.0)$ & & $14(17.7)$ & $50(21.6)$ & & & \\
\hline 2 (important violation) & $9(7.1)$ & $30(8.5)$ & & $5(6.3)$ & $14(6.0)$ & & & \\
\hline 3 (serious violation) & $6(4.8)$ & $20(5.6)$ & & $1(1.3)$ & $6(2.6)$ & & & \\
\hline Mean (SD) & $0.4(0.8)$ & $0.4(0.9)$ & 0.300 & $0.3(0.7)$ & $0.4(0.7)$ & 0.900 & 0.300 & 2 \\
\hline \multicolumn{9}{|l|}{ Case 5 (squat), $n$ (\%) } \\
\hline 0 (no violation) & $20(15.6)$ & $63(17.7)$ & & $17(21.5)$ & $41(18.0)$ & & & \\
\hline 1 (not important violation) & $38(29.7)$ & $81(22.8)$ & & $15(19.0)$ & $58(25.4)$ & & & \\
\hline 2 (important violation) & $48(37.5)$ & $154(43.3)$ & & $37(46.8)$ & $103(45.2)$ & & & \\
\hline 3 (serious violation) & $22(17.2)$ & $58(16.3)$ & & $10(12.7)$ & $26(11.4)$ & & & \\
\hline Mean (SD) & $1.6(1.0)$ & $1.6(1.0)$ & 0.700 & $1.5(1.0)$ & $1.5(0.9)$ & 0.600 & 0.300 & 3 \\
\hline \multicolumn{9}{|l|}{ Case 6 (computer), $n$ (\%) } \\
\hline 0 (no violation) & $2(1.8)$ & $17(5.3)$ & & $5(6.6)$ & $12(5.3)$ & & & \\
\hline 1 (not important violation) & $2(1.8)$ & $13(4.0)$ & & $4(5.3)$ & $8(3.5)$ & & & \\
\hline 2 (important violation) & $21(18.9)$ & $59(18.4)$ & & 15 (19.7) & $26(11.4)$ & & & \\
\hline 3 (serious violation) & $86(77.5)$ & $232(72.3)$ & & $52(68.4)$ & $182(79.8)$ & & & \\
\hline Mean (SD) & $2.7(0.6)$ & $2.6(0.8)$ & 0.200 & $2.5(0.9)$ & $2.7(0.8)$ & 0.300 & 0.100 & 3 \\
\hline
\end{tabular}

${ }^{\mathrm{a}} 64$ medical students and 15 dental students. ${ }^{43}$ b,c,d Comparisons (Mann-Whitney test) between community and hospital physicians (b), physicians and medical students (c), and physicians and law students (d). ' Swiss gold standard (three professors of criminal law in Geneva). SD = standard deviation.

latter. An important finding of the study is that only a minority of physicians considered the violation in cases $1 \mathrm{a}$ or $1 \mathrm{~b}$ to be serious. While more than $70 \%$ of all physicians thought that the violation of confidentiality is severe if a computer specialist takes patient files home, only one-third of physicians thought that revealing the name and disease of a politician to the physician's wife is serious. About the same proportion, one-third, considered that no violation takes place or that this violation is non-important. The remaining one-third considered that the violation in case $1 \mathrm{a}$, although not serious, deserves a score of 2 . The underestimated seriousness of the confidentiality breach in cases 1a and $1 \mathrm{~b}$ might explain why a sizeable percentage of physicians share confidential information with their spouses or friends. ${ }^{26}$
In case 5 , even fewer physicians (18.4\%) felt that a severe violation of confidentiality occurs if a physician talks to a lawyer about a recognisable patient: most physicians thought that the patient is identifiable and even among those who considered the patient identifiable, only $23 \%$ (data not shown in Table 2) evaluated the breach as being serious. The physician in case 5 might have wanted the lawyer or the parliament to help prevent police violence in the future. The message implied in case 5 is: if you want to do something against police violence you can inform about anonymous statistics or cases but be careful about the risk of indirect identification of patients. If the patient is identifiable, you need to ask patient consent first. In order to motivate physicians to change their attitudes, it could be helpful to make them aware of 
what their patients expect from them. Weiss has shown that more than half of studied physicians admitted that they reveal identifiable patient information to their spouses. ${ }^{26}$ Only $17 \%$ of the 177 patients included in Weiss' study were aware that this type of confidentiality breach takes place. Weiss also asked a question that is similar to case 5 from the present study: a total of $60 \%$ of physicians in Weiss' study reported that they tell colleagues about interesting patient histories at parties, and $36 \%$ admitted to telling these stories to nonphysicians during a party, while only $18 \%$ of patients imagined that their physicians spoke to colleagues at parties and only $9 \%$ that the physician revealed medical information about them to non-physicians. Possible reasons for the differences between case 1 and case 5 are that not only students but also physicians are not always aware about the risk of identification, ${ }^{35}$ and that some might find it justified to inform a lawyer about a victim of violence by the police, even against the patient's wish. ${ }^{15-18}$

Non-identification of the breach and/or underestimation of the severity of the violation occurred mostly in the cases in which information was given to the police (case 3 ) or to colleagues (cases 2 and 4). More specific education might be useful. At present, ethics and health law courses often focus too narrowly on those aspects of confidentiality and privacy rights where a conflict exists between confidentiality and a danger to third parties or society. In addition, education should address specific aspects of when information sharing between colleagues or with authorities is allowed and when it is inappropriate because other solutions exist. ${ }^{39}$

The present results differ from those of Lako and Lindenthal, who found a strong reluctance to divulge information to other physicians without the patient's consent. ${ }^{24}$ However, they used vignettes describing the disclosure of information to insurance physicians and occupational health physicians. Doctors and students might more easily recognise the requirement of confidentiality towards this group of physicians than to other groups.

It was not possible to identify a general trait 'respect for confidentiality'. This means that no subgroups of physicians were identified that might benefit from education. By contrast, specific education will be usual for all physicians because most of them seem to be at risk of breaching confidentiality in some situations, especially when information is requested by authorities such as a forensic expert or the police. The fact that more than half of all contacted physicians participated in the teaching exercise shows that interest in this type of education is high.

Physicians' and medical students' attitudes did not vary significantly, except for case 3 . From an optimistic point of view, this means that practical experience has a sizeable effect on a case that occurs in private practice (waiting room). It could also indicate that more experienced physicians are less intimidated by the police. From a more pessimistic point of view, the present results could mean that, in most cases, physician's knowledge stagnates after medical school. Indeed, the sample of future medical professionals used for comparison consisted of students near the end of medical school, that is, at a moment at which knowledge about theoretical subjects such as ethics and legal medicine might be at a maximum. ${ }^{43}$

\section{Strengths and limitations of the study}

The study has some limitations. In Switzerland, the risk for physicians to be sued for a violation of confidentiality is very low. Physicians in this study might have approached the matter from an ethical standpoint and might have tended to see violations as less serious than the law professors. It might be worthwhile to extend the study to professors of moral philosophy, or specialists in health ethics, to see whether they would have come up with the same answers as the professors of law.

By contacting community physicians, the study probably included almost all internists and GPs with a private practice in Geneva because, in principle, they are all members of the AMG. However, although more than half of all contacted physicians participated in the study, a sizeable minority did not. This means that the results might not be representative of all internists and GPs with a private practice in Geneva. Instead they might reflect the attitudes of physicians who are interested in legal and ethical questions and motivated in general to participate in postgraduate training. Therefore the study might have overestimated knowledge and compliance with legal requirements of confidentiality. More motivated physicians who returned the questionnaire might have greater knowledge about confidentiality than participants who did not return the questionnaire. However, if this were the case, it would only reinforce the conclusions of the study that more detailed education about confidentiality is needed.

The fact that few differences were found between hospital physicians, physicians working in private practice, and medical students increases the probability that the study found 'typical' attitudes of current and future physicians in Geneva.

In contrast to medical students, the law students used for comparison were closer to the beginning of their studies, although second year law students can be said to be in the middle of their 3-year curriculum. Their attitudes might change during their ongoing studies and therefore might not be representative of more advanced law students. The answers of the law students from the study samples could therefore more 
closely represent the attitudes prevalent among educated young people early in their university education, rather than specifically those of future lawyers. For the interpretation of the study results, however, it is not very important whether current and future physicians are compared to law students or to a sample of educated young students interested in law.

\section{Implications for future research}

In line with findings from other research, the present study shows that although healthcare professionals know the importance of confidentiality, a substantial percentage of them do not always know exactly how to maintain it in practice. They are unsure of the exact circumstances in which they can divulge information to others in everyday situations..$^{41,42}$ A sizeable percentage of physicians could benefit from education about situations that violate the legal and ethical requirement for confidentiality, especially if colleagues and authorities (police, forensic experts, or coroners) request information. In addition, the seriousness of violations is often underestimated. As shown in case 5 , physicians need to understand the risk of patient identification in order to avoid unjustified violations of confidentiality. Postgraduate teaching programmes should address these specific issues of confidentiality as well as the seriousness of violations. ${ }^{36}$ Similar teaching methods should already be introduced at undergraduate level and their impact evaluated. The present study provides an example of an educational programme and shows that the majority of contacted physicians were interested in the teaching intervention. Questionnaires presenting specific 'traps' to confidentiality are helpful to increase physicians' sensitivity towards respecting confidentiality.

\section{Funding body}

Funding was provided by a research fund of the faculty of medicine, University of Geneva (ME5715)

\section{Competing interests}

The authors have stated that there are none

\section{Acknowledgements}

We thank Timothy Harding for the permission to include the case vignettes, which he has developed and used during many years for a teaching model with medical and law students.

\section{Discuss this article}

Contribute and read comments about this article on the Discussion Forum: http://www.rcgp.org.uk/bjgp-discuss

\section{REFERENCES}

1. Baird G. Confidentiality: what everyone should know, or, rather, shouldn't. Br J Gen Pract 2008; 58(547): 131-133.

2. World Medical Association. Declaration of Helsinki. Seoul: WMA, 2008. http://www.wma.net/e/policy/b3.htm (accessed 2 Sep 2009).

3. British Medical Association. Policy concerning confidentiality. http://web.bma.org.uk/ap.nsf/Content/HubConfidentiality (accessed 20 Aug 2009).

4. Mathews B, Kenny MC. Mandatory reporting legislation in the United States, Canada, and Australia: a cross-jurisdictional review of key features, differences, and issues. Child Maltreat 2008; 13(1): 50-63.
5. Gupta M. Mandatory reporting laws and the emergency physician. Ann Emerg Med 2007; 49(3): 369-376.

6. Houry D, Sachs CJ, Feldhaus KM, Linden J. Violence-inflicted injuries: reporting laws in the fifty states. Ann Emerg Med 2002; 39(1): 56-60.

7. Hall D. Protecting children, supporting professionals. Arch Dis Child 2003; 88(7): 557-559.

8. President's Commission. President's Commission for the Study of Ethical Problems in Medicine and Biomedical and Behavioral Research. Screening and counseling for genetic conditions. Washington, DC: US Government Printing Office, 1983.

9. Australian Medical Association. Code of Ethics 2004. Editorially revised 2006. http://www.ama.com.au/codeofethics (accessed 2 Sep 2009).

10. Lindenthal JJ, Thomas CS. A comparative study of the handling of confidentiality. J Nerv Ment Dis 1980; 168(6): 361-369.

11. Lindenthal JJ, Thomas CS. Psychiatrists, the public, and confidentiality. J Nerv Ment Dis 1982; 170(6): 319-323.

12. Dale R, Barton R, Shepherd J, et al. Why are doctors ambivalent about patients who misuse alcohol? BMJ 1997; 315(7118): 1297-1300.

13. Beran RG. Confidentiality and the management of patients with epilepsy who fail to comply with doctor's advice not to drive: a survey of medical/legal opinions in Australia. Seizure 1998; 7(6): 459-468.

14. Council on Ethical and Judicial Affairs. Physicians and domestic violence. Ethical considerations. American Medical Association. JAMA 1992; 267(23): 3190-3193.

15. Rodriguez MA, Craig AM, Mooney DR, Bauer HM. Patient attitudes about mandatory reporting of domestic violence. Implications for health care professionals. West J Med 1998; 169(6): 337-341.

16. Rodriguez MA, McLoughlin E, Nah G, Campbell JC. Mandatory reporting of domestic violence injuries to the police: what do emergency department patients think? JAMA 2001; 286(5): 580-583.

17. Boyer R, Fortin C, Duval B, et al. Les opinions des medecins quebecois a l'egard du SIDA: Partie II [The opinions of Quebec physicians regarding AIDS: Part II]. Can J Public Health 1994; 85(5): 344-346.

18. Bredfeldt RC, Dardeau FM, Wesley RM, et al. AIDS: family physicians' attitudes and experiences. J Fam Pract 1991; 32(1): 71-75.

19. Moatti JP, Souville M, Obadia Y, et al. Ethical dilemmas in care for HIV infection among French general practitioners. Health Policy 1995; 31(3): 197-210.

20. Simone SJ, Fulero SM. Psychologists' perceptions of their duty to protect uninformed sex partners of HIV-positive clients. Behav Sci Law 2001; 19(3): 423-436.

21. Stevens NG, McCormick TR. What are students thinking when we present ethics cases? An example focusing on confidentiality and substance abuse. J Med Ethics 1994; 20(2): 112-117.

22. Hipshman L. Attitudes towards informed consent, confidentiality, and substitute treatment decisions in southern African medical students: a case study from Zimbabwe. Soc Sci Med 1999; 49(3): 313-328.

23. Self DJ, Lyon-Loftus GT. A model for teaching ethics in a family practice residency. J Fam Pract 1983; 16(2): 355-359.

24. Lako CJ, Lindenthal JJ. Confidentiality in medical practice. J Fam Pract 1990; 31(2): 167-170.

25. Cheng TL, Savageau JA, Sattler AL, DeWitt TG. Confidentiality in health care. A survey of knowledge, perceptions, and attitudes among high school students. JAMA 1993; 269(11): 1404-1407.

26. Weiss BD. Confidentiality expectations of patients, physicians, and medical students. JAMA 1982; 247(19): 2695-2697.

27. Ubel PA, Zell MM, Miller DJ, et al. Elevator talk: observational study of inappropriate comments in a public space. Am J Med 1995; 99(2): 190-194.

28. Mulligan EC. Confidentiality in health records: evidence of current performance from a population survey in South Australia. Med J Aust 2001; 174(12): 637-640.

29. Clark PA. What residents are not learning: observations in an NICU. Acad Med 2001; 76(5): 419-424.

30. Clark PA. Confidentiality and the physician-patient relationship ethical reflections from a surgical waiting room. Med Sci Monit 2002; 8(11): SR31-34.

31. Mlinek EJ, Pierce J. Confidentiality and privacy breaches in a 
university hospital emergency department. Acad Emerg Med 1997; 4(12): 1142-1146

32. Siegler M. Sounding boards. Confidentiality in medicine - a decrepit concept. N Engl J Med 1982; 307(24): 1518-1521.

33. Sokol D, Car J. Protecting patient confidentiality in telephone consultations in general practice. Br J Gen Pract 2006; 56(526): 384-385.

34. Scott K, Dyas JV, Middlemass JB, Siriwardena AN. Confidentiality in the waiting room: an observational study in general practice. $\mathrm{Br} \mathrm{J}$ Gen Pract 2007; 57(539): 490-493.

35. Dyer C. Doctor who revealed patient details cleared by GMC (a patient's case of CJD was presented to journalists with sufficien details to make the patient identifiable). BMJ 2000; 321: 1490.

36. Grady C, Jacob J, Romano C. Confidentiality: a survey in a research hospital. J Clin Ethics 1991; 2(1): 25-30; discussion 30-44.

37. Patients' knowledge and expectations of confidentiality in primary health care: a quantitative study. Br J Gen Pract 2000; 50(460): 901-902.

38. France RD. Law and the general practitioner: confidentiality. BMJ Clin Res Ed) 1981; 283(6285): 197-199.

39. Anonymous. Medical confidentiality and the law. BMJ (Clin Res Ed)
1981; 283: 1062.

40. Ford CA, Millstein SG. Delivery of confidentiality assurances to adolescents by primary care physicians. Arch Pediatr Adolesc Med 1997; 151(5): 505-509.

41. Shrier I, Green S, Solin J, Duarte-Franco E, et al. Knowledge of and attitude toward patient confidentiality within three family medicine teaching units. Acad Med 1998; 73(6): 710-712.

42. Rock EM, Simmons PS. Physician knowledge and attitudes of Minnesota laws concerning adolescent health care. J Pediatr Adolesc Gynecol 2003; 16(2): 101-108.

43. Elger BS, Harding TW. Avoidable breaches of confidentiality: a study among students of medicine and of law. Med Educ 2005; 39(3): 333-337.

44. Elger BS. Factors influencing attitudes towards medical confidentiality among Swiss physicians. J Med Ethics 2009; 35(8): 517-524.

45. Gore DM. Ethical, professional, and legal obligations in clinical practice: a series of discussion topics for postgraduate medical education. Topic 4: confidentiality. Postgrad Med J 2001; 77(909): 443-444.

46. Black D. Iconoclastic ethics. J Med Ethics 1984; 10(4): 179-182. 


\section{Appendix 1. The answers of the law professors.}

The three Swiss professors of criminal law established the following unanimous answers to the seven cases:

In case 1a the politician is clearly identifiable and in case $1 \mathrm{~b}$ the risk of personal identification among the five male politicians is still very high. The physician therefore violates confidentiality even if the name of the politician is not revealed. Score 3 is attributed because no justification or honourable motive exists. Being less familiar with Geneva politicians, several European law professors attributed a milder evaluation (score 2) to the case variant where the name is not revealed.

Case 2 is also an example of a violation of confidentiality. Sharing of information about a patient in the course of referral to a colleague for further investigation is common practice, and in such a situation the consent of the patient may be implicit. ${ }^{45,46}$ However, case 2 does not describe such a consensual referral but a patient-physician conflict in which the physician cannot presume that the patient consents implicitly to the transmission of information. The new physician is not at risk of contracting hepatitis $C$ if they adhere to routine protective measures recommended for contact with blood or secretions of all patients. Therefore, disclosure of information in order to protect the second physician is not justified without the patient's consent. Score 2 is attributed because the physician had an honourable motive, that is, to protect his colleague.

In case 3 the violation of confidentiality is serious (score 3). Physicians are supposed to know that they are not authorised to give any confidential information to the police, except in a case of imminent and grave danger to a third person or society. Theft of a purse does not fulfil these conditions.

Case 4 is also an example of a violation of confidentiality that is unauthorised in Geneva. Before transferring any part of the medical record to a colleague in this case the physician must request authorisation from the competent cantonal commission. The case of a cadaver does not represent an urgent situation, although there may be considerable anxiety in the family members waiting for confirmation of identification. However, the physician could ask to receive the relevant autopsy data and make the comparison himself rather than transmitting the case file. Score 2 is attributed because the physician had an honourable motive. In case 4 , several European law professors attributed either score 1 or score 0 . One explained that they were not convinced that 'confidentiality necessarily survives death' and that the interest of identifying the cadaver overrides confidentiality in this case. Another considered the transmission of the record a prima facie breach of legally required confidentiality, which they consider in this case justified to 'protect the interest of patients or others'. Another who attributed score 1 commented that 'the ultimate issue of public interest would need to be decided by a court if a complaint was made'. Two others made the score dependent on whether an alternative way exists to identify the cadaver. The violation of confidentiality would be justified only if the transmission of the record were the only means to proceed with identification.

In case 5, the physician seriously violates confidentiality. Interestingly, not only Swiss, but also European law professors agreed that in a small town such as Geneva the facts 'recent evacuation of a squat' and the indication of its location renders identification of the patient possible if not likely, if the lawyer raises the issue in the political arena. Disclosing such confidential information against the patient's will at a party is without justification (score 3).

Case 6 describes an unjustified serious (score 3) violation of confidentiality. The question remains open who is responsible for this violation. According to the law in Geneva, the physician is responsible if no contract exists with the computer specialist that declares them to be the physician's 'auxiliary', who are also bound by medical confidentiality; if such a written or proven oral contract exists, the computer specialist is responsible. In addition, the computer specialist could also be found guilty according to the Swiss federal data protection law. 